\title{
Severe Rigid Scoliosis: Review of Management Strategies and Role of Spinal Osteotomies
}

\author{
Pankaj Kandwal ${ }^{1}$, Govindaraja Perumal Vijayaraghavan ${ }^{2}$, Upendra Bidre Nagaraja ${ }^{3}$, Arvind Jayaswal ${ }^{2}$ \\ ${ }^{1}$ Department of Orthopaedics, All India Institute of Medical Sciences (AIIMS), Rishikesh, India \\ ${ }^{2}$ Department of Orthopaedics, Primus Superspeciality Hospital, New Delhi, India \\ ${ }^{3}$ Department of Orthopaedics, Jain Institute of Spine Care \& Research, Bangalore, India
}

Severe rigid curves pose a considerable challenge to the treating spine surgeon. In our practice, approximately $30 \%-40 \%$ of patients with scoliosis present late with severe rigid scoliosis $\left(>90^{\circ}\right.$ and $<30 \%$ correction on bending films). Controversy still exists with regard to the ideal surgical strategy for correcting these rigid curves. Rigid scoliosis often presents in the form of either sharp angular or rounded deformities. Rounded deformities can be effectively managed with an anterior release to loosen the apex and posterior instrumentation (with osteotomies, if required). In contrast, severe rigid scoliosis, which is a sharp angular deformity, is not very amenable to anterior release and is best managed by posterior-only vertebral column resection and posterior instrumentation.

Keywords: Severe rigid scoliosis; Anterior release; Posterior vertebral column resection; Halo traction

\section{Introduction}

In a majority of cases, scoliosis surgery is aimed at cosmesis by achieving a balanced spine. However, severe and rigid scoliotic curves, besides cosmetic concerns, are associated with cardiopulmonary compromise and can lead to significant morbidity and mortality if left untreated. These curves have a greater tendency to continuously progress during adult life, which further amplifies the problem [1]. In extreme cases, they can cause late-onset neurological deficit. Therefore, conservative treatment has no role in the management of severe rigid scoliosis. Surgical management is extremely challenging and fraught with risks; therefore, a consensus on standard treatment is elusive. Although a standard definition of severe curve is missing in the literature, a scoliotic curve is defined as large when the curve magnitude is $\geq 70^{\circ}$ and as rigid when curve flexibility is $\leq 30 \%$ [2]. The difficulty in managing severe rigid scoliosis is high because the spinal deformity is usually stiff, and correction is amenable usually after radical release or osteotomy of the spine. This adds to the duration of surgery and significant blood loss, besides the potentially higher risk of neurologic deficit as well as woundand chest-related complications, among others. However, the benefit of this surgical treatment is potentially farreaching from a cosmetic, pulmonary, and general health perspective, and the prevention of further neurological deterioration and deformity progression may help lengthen lifespan as well as improve the quality of life in many of these patients [3].

Received Oct 19, 2016; Revised Dec 14, 2016; Accepted Jan 4, 2017

Corresponding author: Pankaj Kandwal

Department of Orthopaedics, All India Institute of Medical Sciences (AIIMS), Veerbhadra Marg, Rishikesh (UK) 249203, India

Tel: +91-8475000282, Fax: +91-1352452940, E-mail: pankajkandwal27@gmail.com 
In developing countries, a large proportion of patients with scoliosis present late, especially the underprivileged. In our practice, approximately $30 \%-40 \%$ of patients with scoliosis present late with severe rigid scoliosis $\left(>90^{\circ}\right.$ and $<30 \%$ correction on bending films). There is still no consensus, as highlighted above, in the management of these rigid curves. Combined anterior and posterior or singlestage posterior-only radical release/osteotomies with instrumentation are generally required for the correction of these deformities. However, in the past decade, there has been a shift to the posterior-only approach with multiple osteotomies and vertebral column resections for the correction of all rigid deformities [2,4-9]. At present, the role of anterior release has become questionable, with good results from the posterior approach alone. However, specific indications for a combined as well as a posterior-only approach are lacking based on curve morphology. Thus, we reviewed the literature on these difficult management problems.

Severe and rigid scoliosis has been a subject of review
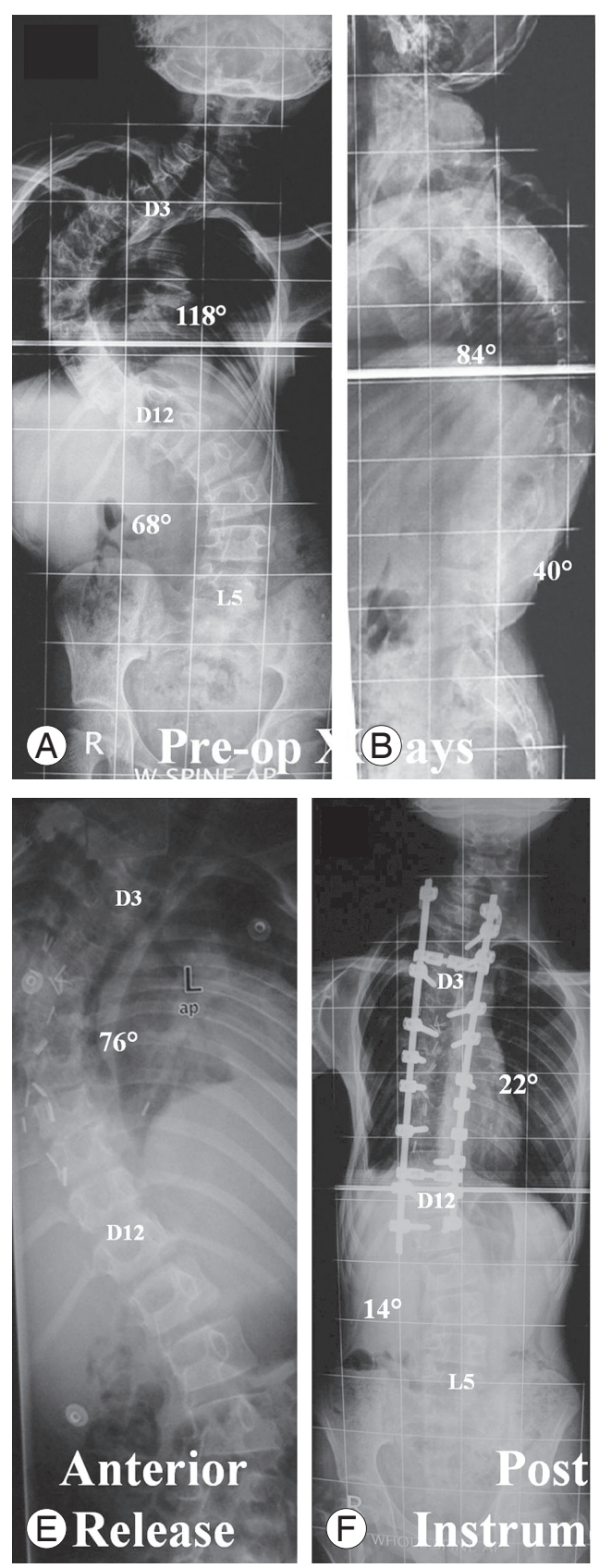
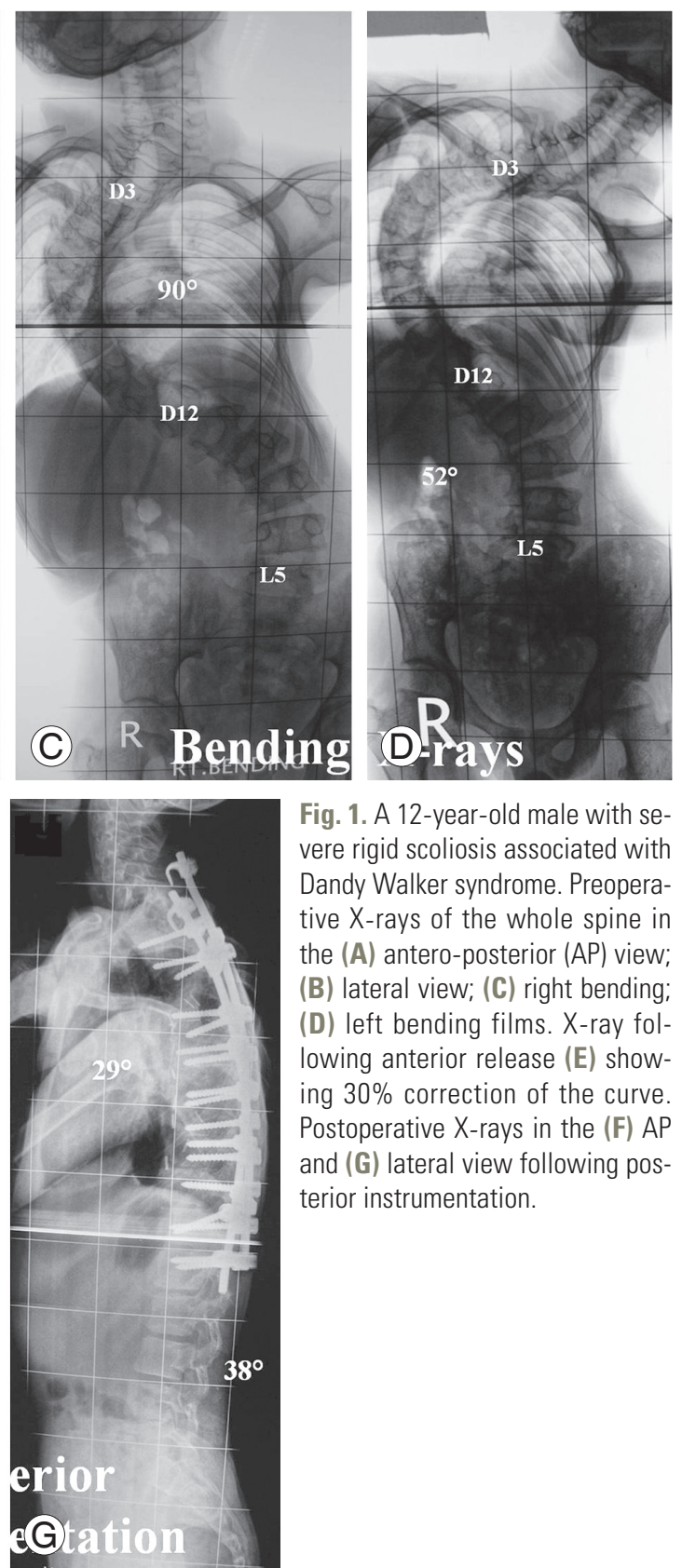

Fig. 1. A 12-year-old male with severe rigid scoliosis associated with Dandy Walker syndrome. Preoperative $X$-rays of the whole spine in the (A) antero-posterior (AP) view; (B) lateral view; (C) right bending; (D) left bending films. X-ray following anterior release (E) showing 30\% correction of the curve. Postoperative $X$-rays in the (F) AP and $(\mathbf{G})$ lateral view following posterior instrumentation. 
and interest for multiple authors [2,5,10-24]. Sucato [3] reports that severe spinal deformity should be distinguished from the more common adolescent idiopathic scoliosis deformity in that both the spine and the chest wall are affected. He further states that posterior softtissue release involving resection of the interspinous ligament and ligamentum flavum, with wide facetectomies at all levels, pedicle subtraction osteotomy (PSO), vertebral column resection (VCR), and anterior release involving rib head resection, vertebral body decancellation as "Spine \& Chest Mobilization" techniques are to be used with the increasing severity of the curve [3].

\section{Anterior Release and Posterior Instrumentation}

Anterior release and posterior instrumentation, either in single or 2 stages, is one of the standard treatments for the management of rigid scoliosis (Figs. 1,2). Anterior release may be done either by traditional open thoracotomy [16] or by a thoracoscopic approach [22]. The role of anterior release has been proven in various cadaveric studies [2527]. Unilateral resection of the rib head joint after partial discectomy on the same side produces significant coupled motions in lateral bending and axial rotation, resulting in a significant decrease in thoracic spinal stability and integrity $[25,26]$, which can facilitate segmental correction in scoliotic deformities. Similarly, Wollowick et al. [27] in a biomechanical cadaveric study found that an
$8.8 \%$ to $71.9 \%$ increase in the amount of axial rotation was achieved by a posterior release, whereas resection of anterior structures led to a $141 \%$ to $288 \%$ increase in rotation. This study indicates that, although many surgeons favor a single posterior approach to correct severe spinal deformity, anterior release may be needed to maximize 3-dimensional correction. They concluded that anterior release generated significantly more thoracic rotation than posterior osteotomy in biomechanical testing of human cadaveric spines [27]. These authors, in a previous study of anterior release and posterior instrumentation for severe rigid round curves, found that preoperative Cobb angle of $116.6^{\circ}$ (range, $101^{\circ}-124^{\circ}$ ) improved to $74.0^{\circ}$ (range, $54^{\circ}-86^{\circ}$ ) after anterior release: $29.4 \%$ correction and the final postoperative Cobb angle after posterior instrumentation was $26.5^{\circ}$ (range, $22^{\circ}-32^{\circ}$ ), with a final $76 \%$ correction [20]. Anterior release is, however, associated with prolonged hospital stay and chest-related complications. It adversly affects the pulmonary function test [28], which in many cases is already compromised.

Other procedures including the use of halo traction preoperatively, peroperatively, or halo traction after release (anterior or posterior) have been reported and favored by many surgeons [8,17-21]. Similarly, anterior release with apical derotation and anterior fixation followed by posterior correction and instrumentation (staged) have been reported too, with good results [16].
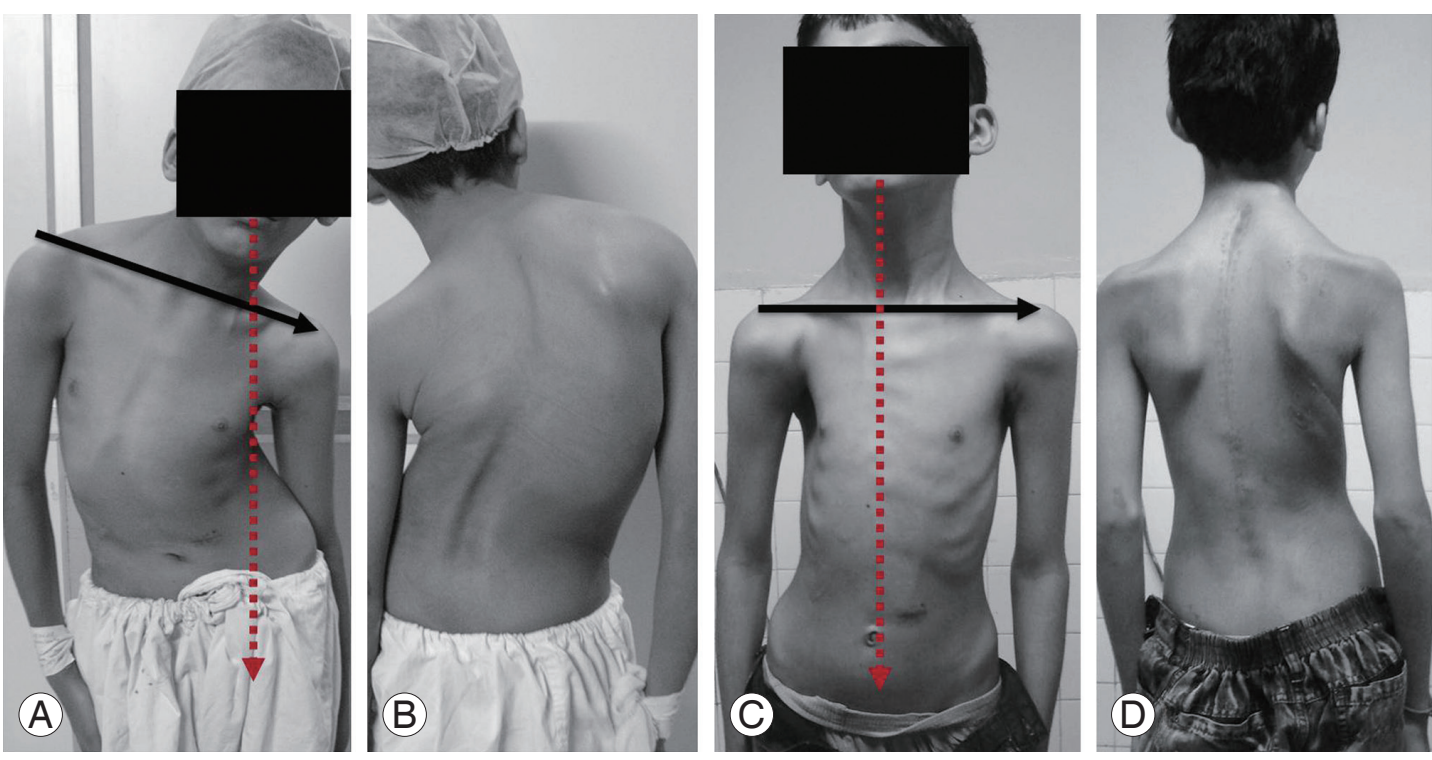

Fig. 2. A 12-year-old male with severe rigid scoliosis associated with Dandy Walker syndrome (A, B). Good shoulder balance (C) and coronal alignment (D) were achieved following staged anterior release and posterior instrumentation. 


\section{Anterior and Posterior Instrumentation}

Another technique reported in the correction of rigid curves involves combined anterior release and instrumented fusion followed by a posterior instrumented corrective fusion (Figs. 3, 4). Bullman et al. [12] reported on a prospective clinical and radiographic evaluation of 33 consecutive patients with severe and rigid idiopathic scoliosis (average Cobb angle $93^{\circ}$, flexibility on bending films $23 \%)$ treated with combined anterior and posterior instru- mentation with a minimum follow-up of 2 years. Frontal plane correction of the primary curve averaged $67 \%$, with an average loss of correction of $2^{\circ}$ [12]. Advantages of anterior thoracic instrumentation includes shortening of the convexity of the thoracic curve without a posterior derotation maneuver that would prevent the lumbar curve from decompensating [29]. In addition, by removing the disc, better correction of thoracic hypokyphosis could be obtained [29].
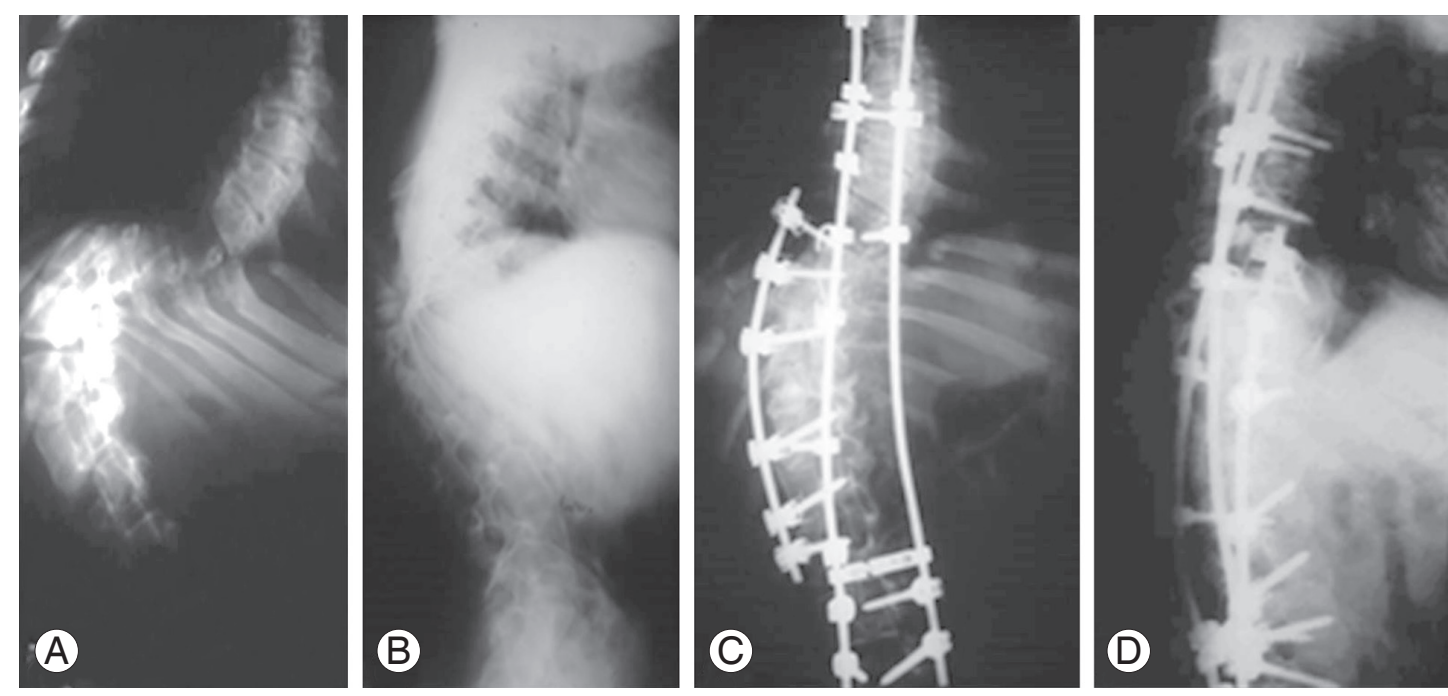

Fig. 3. Severe rigid scoliosis with preoperative $X$-ray: antero-posterior view (A) and lateral view (B). Postoperative X-rays showing stage I anterior release and anterior instrumentation at the apical six vertebrae; Stage II, posterior pedicle screw instrumentation (C, D).
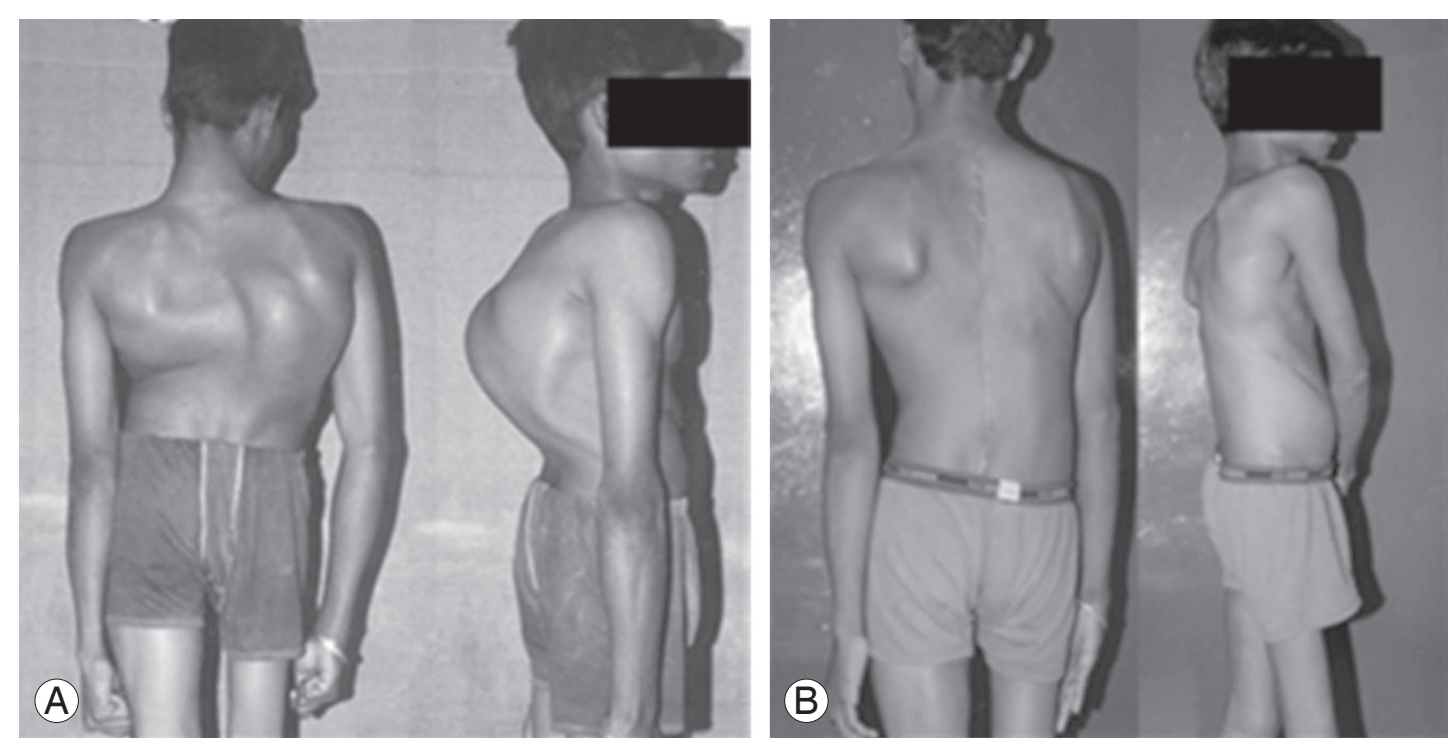

Fig. 4. Preoperative (A) and postoperative (B) clinical picture of the patient who underwent Stage I anterior release and anterior instrumentation at the apical six vertebrae; Stage II, posterior pedicle screw instrumentation. 


\section{Role of Halo traction}

Some authors have used Halo traction (Fig. 5) preoperatively or between the anterior and posterior procedures $[9,10,15,19,23,30]$. Qiu et al. [10] showed a $57.5 \%$ correction of major curve by using Halo-femoral traction after anterior release before taking up for posterior instrumentation. However, four of their patients developed brachial plexus injury. Similarly, a 71\% correction (average pre-traction curve was $95^{\circ}$ and the average pre-traction curve on bending was $73^{\circ}$; the final traction average curve was $44^{\circ}$ ) was achieved by Mehlman et al. [15] by using Halo-femoral traction between the anterior and posterior procedures. Tokunaga et al. [24] showed an average correction of $46 \%$ in lateral curvature at final follow-up, where vertebral decancellation was performed as an anterior procedure, and until posterior instrumentation, halo traction was carried out. Various complications related to Halo traction, such as pin loosening, pin tract infection, and, rarely, brain abscess, cranial nerve palsies, and other traction-related neurological adverse events, have to be kept in mind before planning the procedure.

The literature, furthermore, reports on the reverse think-

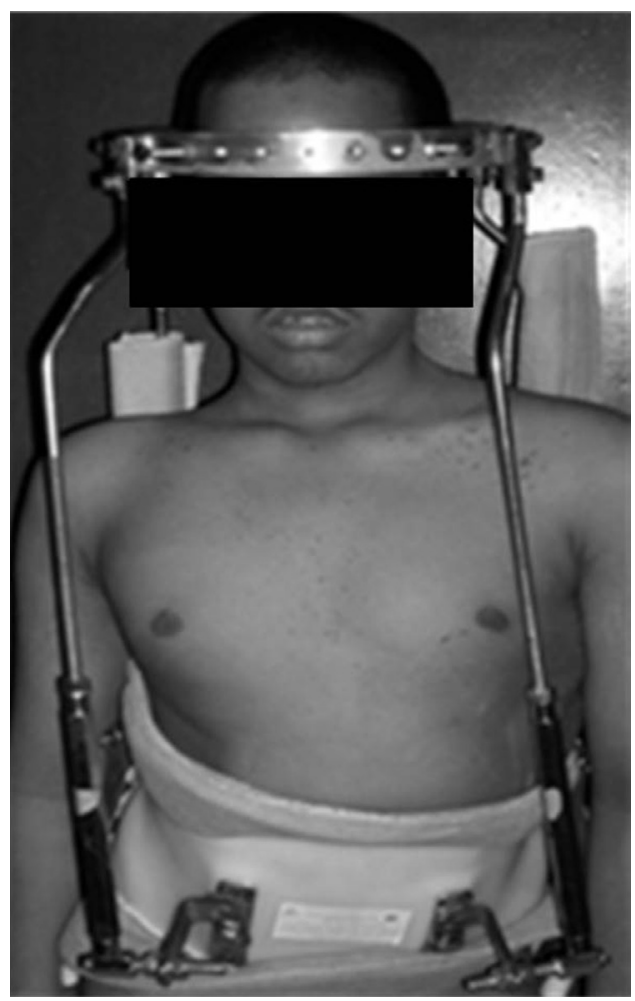

Fig. 5. Halo traction applied after anterior release in case of rigid scoliosis. ing of posterior release followed by anterior instrumented correction for short and rigid thoracic curves. Harms et al. [31] recommend a posterior release prior to an anterior instrumented correction and fusion in thoracic curves larger than $75^{\circ} \mathrm{Cobb}$ angles. Similarly, Bullman et al. [12] carried out posterior release before going on with anterior instrumentation when the Cobb angle exceeded $100^{\circ}$ or flexibility was $<20^{\circ}$. Various studies on anterior release and posterior Instrumentation are mentioned in Table 1.

\section{Posterior-Only Vertebral Column Resection}

VCR includes removal of the posterior elements and the entire vertebral body ( $\geq 1$ bodies) with the discs above and below. In a study by Bradford and Tribus [32], 24 patients with fixed coronal imbalance were treated with anterior and posterior vertebral column resection, spinal shortening and realignment, posterior segmental fixation, and fusion. Coronal balance was improved by $82 \%$, whereas scoliosis was improved by $52 \%$. A total of 31 complications were identified in 14 patients. The most common complication was a dural tear, which occurred in eight patients; neurologic complications occurred in three patients, and other complications included pulmonary infection, wound-related problems, and pseudoarthrosis [32]. The authors in a series of 24 patients (unpublished) with angular kyphoscoiosis who underwent posterior vertebral column resection (PVCR) showed $71 \%$ correction of deformity in coronal (preoperative $70.75^{\circ} \pm 2.3^{\circ}$ to postoperative $20.41^{\circ} \pm 6^{\circ}$ ) and $70 \%$ correction in the sagittal plane (preoperative, $94.12^{\circ} \pm 13.21^{\circ}$ to postoperative, $\left.27.54^{\circ} \pm 6.6^{\circ}\right)$. PVCR is a powerful tool to correct a complex spinal deformity in a single stage (Figs. 6, 7). Numerous authors recently have resorted to PVCR for management of rigid deformities of the spine. The largest series of posterior vertebral column resection till date is by Suk et al. $[7,33,34]$. The average correction of deformity was $61.9 \%$ in the coronal plane and $45.2 \%$ in the sagittal plane in the series of 70 patients. However, the rate of complication was high in his series with two complete cord injuries $[7,34]$. In a separate study by Lenke et al. [8], cases with severe scoliosis had a correction of $69 \%$; correction was $54 \%, 63 \%$, and $56 \%$ for cases with global kyphosis, angular kyphosis, and combined kyphoscoliosis, respectively. The average blood loss was $1,103 \mathrm{~mL}$ and the mean operating time was 9 hours 37 minutes. No spinal cord-related neurologic deficits were seen in any of the patients in this 
Table 1. Major published studies by various authors on anterior release and posterior instrumentation

\begin{tabular}{|c|c|c|c|c|c|c|}
\hline Study & $\begin{array}{l}\text { No./ } \\
\text { Average } \\
\text { age (yr) }\end{array}$ & Procedure & $\begin{array}{c}\text { Preop } \\
\text { Cobbs }\left({ }^{\circ}\right)\end{array}$ & $\begin{array}{l}\text { Average } \\
\text { correction } \\
(\%)\end{array}$ & Complications & $\begin{array}{l}\text { Follow-up } \\
\qquad(\mathrm{mo})\end{array}$ \\
\hline Yamin et al. [21] & $21 / 15.3$ & $\begin{array}{l}\text { II-Anterior release+ } \\
\text { halo-pelvic traction } \\
\text { II-Posterior instrumentation }\end{array}$ & 110.5 & 65.2 & One-motor deficit & 51 \\
\hline Bullmann et al. [12] & $33 /-$ & $\begin{array}{l}\text { I-Anterior release+ventral } \\
\text { derotation spondylodesis } \\
\text {-Zielke instrumentation. } \\
\text { II-Posterior instrumentation }\end{array}$ & 93.0 & 67.0 & $\begin{array}{l}\text { No neurological complications, } \\
\text { deep wound infections or } \\
\text { pseudarthrosis }\end{array}$ & Min-2 yr \\
\hline Qiu et al. [10] & $24 / 17$ & $\begin{array}{l}\text { Anterior release+posterior } \\
\text { instrumentation. }\end{array}$ & 98.0 & 41.0 & $\begin{array}{l}\text { One-revision surgery of hook } \\
\text { displacement }\end{array}$ & 18 \\
\hline Hamzaoglu et al. [9] & $15 / 17.8$ & $\begin{array}{l}\text { Posterior only pedicle } \\
\text { screw instrumentation+ } \\
\text { intraoperative halo-femoral } \\
\text { traction }\end{array}$ & $>100$ & 51.0 & Not reported & 56 \\
\hline Ruf et al. [16] & $22 / 13.4$ & $\begin{array}{l}\text { Anterior release and } \\
\text { posterior instrumentation }\end{array}$ & 80.0 & 80.0 & $\begin{array}{l}\text { Pleural effusion-6 } \\
\text { Wound infections-2 } \\
\text { Temporary neurological deficit-1 }\end{array}$ & 2 to $7 \mathrm{yr}$ \\
\hline Kandwal et al. [20] & $21 / 14.4$ & $\begin{array}{l}\text { Anterior release and } \\
\text { posterior instrumentation }\end{array}$ & 116.6 & 76.0 & $\begin{array}{l}\text { Prolonged chest tube-1 } \\
\text { Basal atelectasis-2 } \\
\text { Loss of motor evoked } \\
\text { potential signal-1 } \\
\text { Hook pull out-1 } \\
\text { Superficial infection-1 } \\
\text { Skin necrosis-1 }\end{array}$ & $32(24-55)$ \\
\hline
\end{tabular}
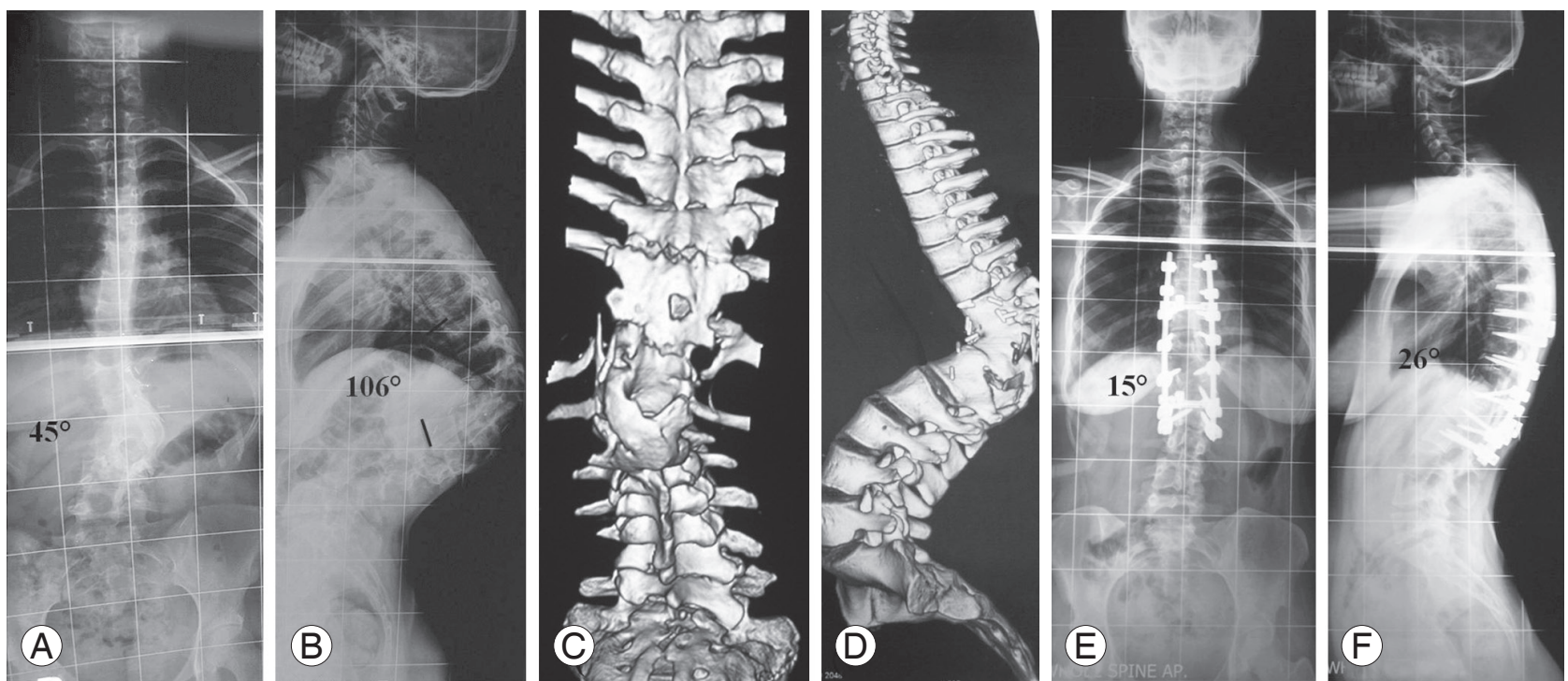

Fig. 6. A 15-year-old female with congenital angular kyphoscoliosis. Preoperative $X$-rays of the whole spine in the (A) antero-posterior (AP) and (B) lateral views. Computed tomography scan with three-dimensional reconstruction (C, D). Postoperative X-rays in the (E) AP and (F) lateral views following posterior-only vertebral column resection.

series [8]. Few authors have attempted modifications of the above two procedures with good results. Chang [2] assessed the efficacy and clinical value of the cantilever bending technique as a technique for correcting large $\left(70^{\circ}\right)$ and rigid (flexibility, 30\%) scoliosis. The deformity correction was $67.1 \%$ (range, $51 \%-74 \%$ ) in the coronal plane. In 

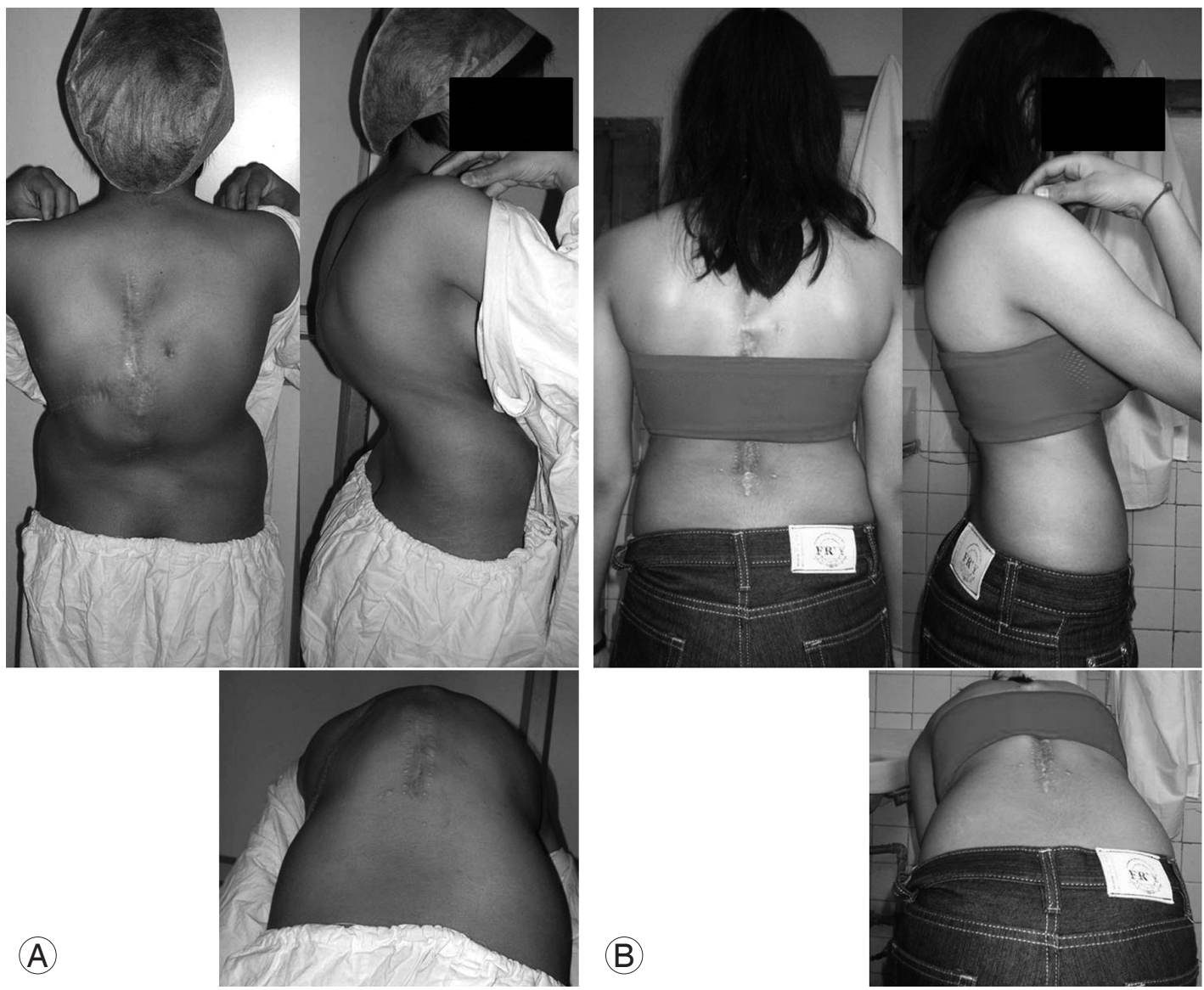

Fig. 7. A 15-year-old female with congenital angular kyphoscoliosis (A). Excellent clinical correction (B) of kyphoscoliosis following posterior-only vertebral column resection.

a prospective study reporting on the efficacy of a modified technique of concave rib osteotomy in conjunction with posterior instrumented fusion in the treatment of severe and rigid curves in patients with adolescent idiopathic scoliosis, El Masry et al. [4] showed $68 \%$ correction in the mean postoperative frontal plane. However, the incidence of pulmonary complications was $11.5 \%$.

Various studies on VCR are elucidated in Table $2[7,8$, $32,35,36]$.

\section{Authors' Approach, Classification, and Preferred Method}

Regardless of etiology, authors classified severe rigid deformity of spine based on sagittal and coronal profiles. The authors believe that, in large rigid curve with a gradual and round deformity in both coronal and sagittal planes, a good circumferential anterior release gives the surgeon a markedly less rigid curve during posterior instrumented correction and avoids or minimizes the requirement of posterior radical osteotomies, required for obtaining correction of these rigid curve by posterior alone methods. Anterior release is an excellent tool in the staged correction of severe rigid curves with a rounded configuration. In the first stage, anterior loosening is done by the traditional thoracotomy approach. Anterior release includes 4-5 level of radical discectomies at the apex of the curve, and sometimes involves cutting of the posterior longitudinal ligament and resection of convex rib head (from the costovertebral and costotransverse joints). The disc space is later packed with morselized graft obtained from the resected rib and rib heads. In the second stage, posterior surgery is done after an interval of 10-14 days. Posterior osteotomies such as Ponte's and facetectomies ensure $360^{\circ}$ release of the spine after good anterior release. Asymmetric PSO is added at the apex of the deformity where the Cobb angle exceeds $120^{\circ}$ or where thoracic hyperkyphosis is encountered. Good to excellent correction 
Table 2. Published series on vertebral column resection for correction of severe rigid scoliosis

\begin{tabular}{|c|c|c|c|c|c|c|c|c|}
\hline Author & No. & $\begin{array}{c}\text { Av } \\
\text { vertebrae } \\
\text { resected }\end{array}$ & Approach & $\begin{array}{c}\text { Av } \\
\text { preoperative } \\
\text { curve }\left(^{\circ}\right)\end{array}$ & $\begin{array}{l}\text { Av curve } \\
\text { correction } \\
(\%)\end{array}$ & $\begin{array}{l}\text { Av blood } \\
\text { loss (mL) }\end{array}$ & $\begin{array}{l}\text { Av } \\
\text { operative } \\
\text { time }\end{array}$ & Complications \\
\hline Bradford et al. [32] & 24 & 1.3 & $\begin{array}{l}\text { Anterior \& } \\
\text { posterior }\end{array}$ & 103.0 & 52 & 5,500 & $>12 \mathrm{hr}$ & $\begin{array}{l}\text { Dural tear -8 } \\
\text { Neurological complication-3 } \\
\text { Pulmonary complications-6 } \\
\text { Pseudarthrosis-2 }\end{array}$ \\
\hline Zhou et al. [35] & 16 & - & $\begin{array}{l}\text { Anterior \& } \\
\text { posterior }\end{array}$ & 99.3 & 67 & 1,916 & 466 min & $\begin{array}{l}\text { Malposition of pedicle } \\
\text { screw-1 } \\
\text { Malposition cage-2 } \\
\text { Prolonged ventilatory } \\
\text { support-1 }\end{array}$ \\
\hline Suk et al. [7] & 16 & 1.3 & Posterior & 109.0 & 59 & 7,034 & $6 \mathrm{hr} 11 \mathrm{~min}$ & $\begin{array}{l}\text { Paraplegia-2 } \\
\text { Hematoma-1 } \\
\text { Hemopneumothorax-1 } \\
\text { Proximal junctional } \\
\text { kyphosis-1 }\end{array}$ \\
\hline Lenke et al. [8] & 43 & 1.5 & Posterior & 92.0 & 61 & 1,103 & $9 \mathrm{hr} 37 \mathrm{~min}$ & $\begin{array}{l}\text { Transient nerve root palsy-2 } \\
\text { Wound infection-1 }\end{array}$ \\
\hline Wang et al. [36] & 24 & - & Posterior & $\begin{array}{c}87.3 \\
\text { (segmental } \\
\text { kyphosis) }\end{array}$ & 87 & 994 & 293 min & $\begin{array}{l}\text { Screw pullout-1 } \\
\text { Spinal cord injury-1 } \\
\text { Nerve root injury-1 } \\
\text { Proximal junction kyphosis-1 }\end{array}$ \\
\hline
\end{tabular}

$A v$, average.

may be anticipated with less inadvertent traction/tension on the cord using these less aggressive osteotomies. Thus, the need to resort to a more morbid and risky vertebral column resection is eliminated.

Rigid scoliosis with a sharp angular deformity, on the other hand, does not greatly benefit from anterior release and is best tackled by posterior three-column osteotomies and instrumentation. Angular scoliosis/kyphoscoliosis, either due to rapid progression, congenital etiology, healed tuberculosis, or neurofibromatosis, has the deformity predominantly along the sagittal axis. Single-stage posterioronly three-column osteotomy with, preferably, a PVCR is an appropriate procedure for these deformities where the desired correction in both coronal and sagittal planes may be achieved with resection at relatively few spinal segments.

The PVCR, a popular method for deformity correction for a severe rigid and rounded curve, would mean more than one osteotomy for optimal curve correction and spinal balance. This would not only increase the duration of surgery and blood loss but also subjects the spinal cord to inadvertent risk of neurological injury. An additional anterior release in these rounded deformities along with lesser extent posterior osteotomies (PSO, Ponte's) during second-stage posterior instrumentation can obviate morbidity without compromising on the desired correction both in coronal and sagittal planes.

The authors also stress that the incidence of neurological complications may be lessened by using motor evoked potential during the surgery. Surgeries for severe rigid scoliosis should not be attempted in the absence of intraoperative neuromonitoring.

\section{Conclusions}

The key to successful treatment of rigid scoliosis is circumferential release. The authors propose that a staged anterior release and posterior instrumentation (with minimal osteotomies, if required) provides a $360^{\circ}$ release of the vertebral column and is a good option for patients with rigid and rounded spinal deformities in comparison to posterior-only three-column osteotomies that involve greater morbidity. On the other hand, PVCR is suited for rigid sharp and angular deformities of the spine, providing good correction with single-stage posterior instrumentation. 


\section{Conflict of Interest}

No potential conflict of interest relevant to this article was reported.

\section{References}

1. Agabegi SS, Kazemi N, Sturm PF, Mehlman CT. Natural history of adolescent idiopathic scoliosis in skeletally mature patients: a critical review. J Am Acad Orthop Surg 2015;23:714-23.

2. Chang KW. Cantilever bending technique for treatment of large and rigid scoliosis. Spine (Phila Pa 1976) 2003;28:2452-8.

3. Sucato DJ. Management of severe spinal deformity: scoliosis and kyphosis. Spine (Phila Pa 1976) 2010;35: 2186-92.

4. El Masry MA, Saleh AM, McWilliams AB, Tsiridis E, Salah H, El Hawary YK. Concave rib osteotomy: a modified technique revisited. Eur Spine J 2007;16: 1600-3.

5. Suk SI, Kim JH, Cho KJ, Kim SS, Lee JJ, Han YT. Is anterior release necessary in severe scoliosis treated by posterior segmental pedicle screw fixation? Eur Spine J 2007;16:1359-65.

6. Xie J, Wang Y, Zhao Z, et al. Posterior vertebral column resection for correction of rigid spinal deformity curves greater than 100 degrees. J Neurosurg Spine 2012;17:540-51.

7. Suk SI, Chung ER, Kim JH, Kim SS, Lee JS, Choi WK. Posterior vertebral column resection for severe rigid scoliosis. Spine (Phila Pa 1976) 2005;30:1682-7.

8. Lenke LG, Sides BA, Koester LA, Hensley M, Blanke KM. Vertebral column resection for the treatment of severe spinal deformity. Clin Orthop Relat Res 2010; 468:687-99.

9. Hamzaoglu A, Ozturk C, Aydogan M, Tezer M, Aksu $\mathrm{N}$, Bruno MB. Posterior only pedicle screw instrumentation with intraoperative halo-femoral traction in the surgical treatment of severe scoliosis $(>100$ degrees). Spine (Phila Pa 1976) 2008;33:979-83.

10. Qiu Y, Liu Z, Zhu F, et al. Comparison of effectiveness of Halo-femoral traction after anterior spinal release in severe idiopathic and congenital scoliosis: a retrospective study. J Orthop Surg Res 2007;2:23.

11. Zhou C, Liu L, Song Y, et al. Anterior release internal distraction and posterior spinal fusion for severe and rigid scoliosis. Spine (Phila Pa 1976) 2013;38:E14117.

12. Bullmann V, Halm HF, Schulte T, Lerner T, Weber TP, Liljenqvist UR. Combined anterior and posterior instrumentation in severe and rigid idiopathic scoliosis. Eur Spine J 2006;15:440-8.

13. Watanabe K, Lenke LG, Bridwell KH, et al. Comparison of radiographic outcomes for the treatment of scoliotic curves greater than 100 degrees: wires versus hooks versus screws. Spine (Phila Pa 1976) 2008;33:1084-92.

14. Gum JL, Lenke LG, Bumpass D, et al. Does planned staging for posterior-only vertebral column resections in spinal deformity surgery increase perioperative complications? Spine Deform 2016;4:131-7.

15. Mehlman CT, Al-Sayyad MJ, Crawford AH. Effectiveness of spinal release and halo-femoral traction in the management of severe spinal deformity. J Pediatr Orthop 2004;24:667-73.

16. Ruf M, Letko L, Matis N, Merk HR, Harms J. Effect of anterior mobilization and shortening in the correction of rigid idiopathic thoracic scoliosis. Spine (Phila Pa 1976) 2013;38:E1662-8.

17. Teixeira da Silva LE, de Barros AG, de Azevedo GB. Management of severe and rigid idiopathic scoliosis. Eur J Orthop Surg Traumatol 2015;25 Suppl 1:S7-12.

18. Chang DG, Yang JH, Lee JH, et al. Pediatric posterior vertebral column resection (pvcr): before and after ten years of age: greater than 10-year follow-up. Spine (Phila Pa 1976) 2016;41:E1271-8.

19. Rinella A, Lenke L, Whitaker C, et al. Perioperative halo-gravity traction in the treatment of severe scoliosis and kyphosis. Spine (Phila Pa 1976) 2005;30:47582.

20. Kandwal P, Goswami A, Vijayaraghavan G, et al. Staged anterior release and posterior instrumentation in correction of severe rigid scoliosis (Cobb angle $>100$ degrees). Spine Deform 2016;4:296-303.

21. Yamin S, Li L, Xing W, Tianjun G, Yupeng Z. Staged surgical treatment for severe and rigid scoliosis. J Orthop Surg Res 2008;3:26.

22. Cheung KM, Wu JP, Cheng QH, Ma BS, Gao JC, Luk KD. Treatment of stiff thoracic scoliosis by thoracoscopic anterior release combined with posterior instrumentation and fusion. J Orthop Surg Res 2007; 2:16.

23. Sponseller PD, Takenaga RK, Newton $\mathrm{P}$, et al. The use 
of traction in the treatment of severe spinal deformity. Spine (Phila Pa 1976) 2008;33:2305-9.

24. Tokunaga M, Minami S, Kitahara H, Isobe K, Nakata Y, Moriya H. Vertebral decancellation for severe scoliosis. Spine (Phila Pa 1976) 2000;25:469-74.

25. Takeuchi T, Abumi K, Shono Y, Oda I, Kaneda K. Biomechanical role of the intervertebral disc and costovertebral joint in stability of the thoracic spine: a canine model study. Spine (Phila Pa 1976) 1999;24: 1414-20.

26. Yao X, Blount TJ, Suzuki N, et al. A biomechanical study on the effects of rib head release on thoracic spinal motion. Eur Spine J 2012;21:606-12.

27. Wollowick AL, Farrelly EE, Meyers K, et al. Anterior release generates more thoracic rotation than posterior osteotomy: a biomechanical study of human cadaver spines. Spine (Phila Pa 1976) 2013;38:15405.

28. Kim YJ, Lenke LG, Bridwell KH, Cheh G, Sides B, Whorton J. Prospective pulmonary function comparison of anterior spinal fusion in adolescent idiopathic scoliosis: thoracotomy versus thoracoabdominal approach. Spine (Phila Pa 1976) 2008;33:1055-60.

29. Betz RR, Harms J, Clements DH 3rd, et al. Comparison of anterior and posterior instrumentation for correction of adolescent thoracic idiopathic scoliosis. Spine (Phila Pa 1976) 1999;24:225-39.

30. Koller H, Zenner J, Gajic V, Meier O, Ferraris L, Hitzl
W. The impact of halo-gravity traction on curve rigidity and pulmonary function in the treatment of severe and rigid scoliosis and kyphoscoliosis: a clinical study and narrative review of the literature. Eur Spine J 2012;21:514-29.

31. Harms J, Jeszenszky D, Beele B. Ventral correction of thoracic scoliosis. In: Bridwell $\mathrm{KH}$, editor. The textbook of spinal surgery. 2nd ed. Philadelphia: Lippincott-Raven; 1997. p.611-26.

32. Bradford DS, Tribus CB. Vertebral column resection for the treatment of rigid coronal decompensation. Spine (Phila Pa 1976) 1997;22:1590-9.

33. Kim SS, Cho BC, Kim JH, et al. Complications of posterior vertebral resection for spinal deformity. Asian Spine J 2012;6:257-65.

34. Suk SI, Kim JH, Kim WJ, Lee SM, Chung ER, Nah $\mathrm{KH}$. Posterior vertebral column resection for severe spinal deformities. Spine (Phila Pa 1976) 2002;27: 2374-82.

35. Zhou C, Liu L, Song Y, et al. Anterior and posterior vertebral column resection for severe and rigid idiopathic scoliosis. Eur Spine J 2011;20:1728-34.

36. Wang S, Aikenmu K, Zhang J, et al. The aim of this retrospective study is to evaluate the efficacy and safety of posterior-only vertebral column resection (PVCR) for the treatment of angular and isolated congenital kyphosis. Eur Spine J 2015 Dec 11 [Epub]. http://dx.doi.org/10.1007/s00586-015-4344-9. 